\title{
Duodenal obstruction by a gallstone (Bouveret's syndrome) managed by endoscopic stone extraction: A case report and review
}

Franzjosef Schweiger MD FRCPC FACP FACG, Rowen Shinder MD FRCPC

F Schweiger, R Shinder. Duodenal obstruction by a gallstone (Bouveret's syndrome) managed by endoscopic stone extraction: A case report and review. Can J Gastroenterol 1997;11(6):493-496. Gastric outlet obstruction caused by a large gallstone in the duodenum or pylorus (Bouveret's syndrome) is a rare complication of gallstone disease. The presenting symptoms are often nonspecific and include nausea, vomiting, epigastric pain and a history of gallbladder disease. Although the diagnosis is established only at surgery in many cases, preoperative recognition by imaging techniques and endoscopy is desirable. Surgical treatment aims at removal of the ectopic gallstone, closure of the fistula and cholecystectomy. A case of Bouveret's syndrome is presented where endoscopic extraction of the duodenal gallstone was accomplished providing definitive treatment for this patient.

Key Words: Bouveret's syndrome, Cholecystoduodenal fistula, Endoscopic stone extraction
Obstruction duodénale par calcul biliaire

(syndrome de Bouveret) traitée par extraction endoscopique : rapport de cas et revue de la littérature

RÉSUMÉ : L'obstruction du bulbe duodénal causée par la présence d'un calcul biliaire dans le duodénum ou le pylore (syndrome de Bouveret) est une complication rare de la lithiase biliaire. Les symptômes typiques sont souvent non spécifiques : nausées, vomissements, douleurs épigastriques et antécédents de maladie vésiculaire. Bien que le diagnostic ne soit confirmé qu'à la chirurgie dans de nombreux cas, la reconnaissance préopératoire au moyen de techniques d'imagerie et d'endoscopie est souhaitable. Le traitement chirurgical vise l'élimination du calcul ectopique et la fermeture de la fistule et englobe la cholécystectomie. Nous présentons ici un cas de syndrome de Bouveret où l'extraction endoscopique du calcul biliaire duodénal a été réalisée, offrant de ce fait un traitement définitif chez le patient.
B ouveret's syndrome is a rare complication of gallstone disease, with fewer than 200 cases described in the literature (1). It is defined by the formation of a cholecystoduodenal or choledochoduodenal fistula with passage of a gallstone into the duodenal bulb or pylorus leading to gastric outlet obstruction. The clinical diagnosis is frequently missed preoperatively, and until recently, surgery was considered to be the only possible treatment (2).

We describe a patient with Bouveret's syndrome who was diagnosed and successfully treated endoscopically.

Department of Internal Medicine (Gastroenterology) and Pathology, South-East Health Care Corporation, The Moncton Hospital, Moncton, New Brunswick

Correspondence and reprints: Dr F Schweiger, 100 Arden Street, Suite 405, Moncton, New Brunswick E1C 4B7. Telephone 506-858-8441, fax 506-858-0859

Received for publication December 13, 1996. Accepted April 17, 1997 


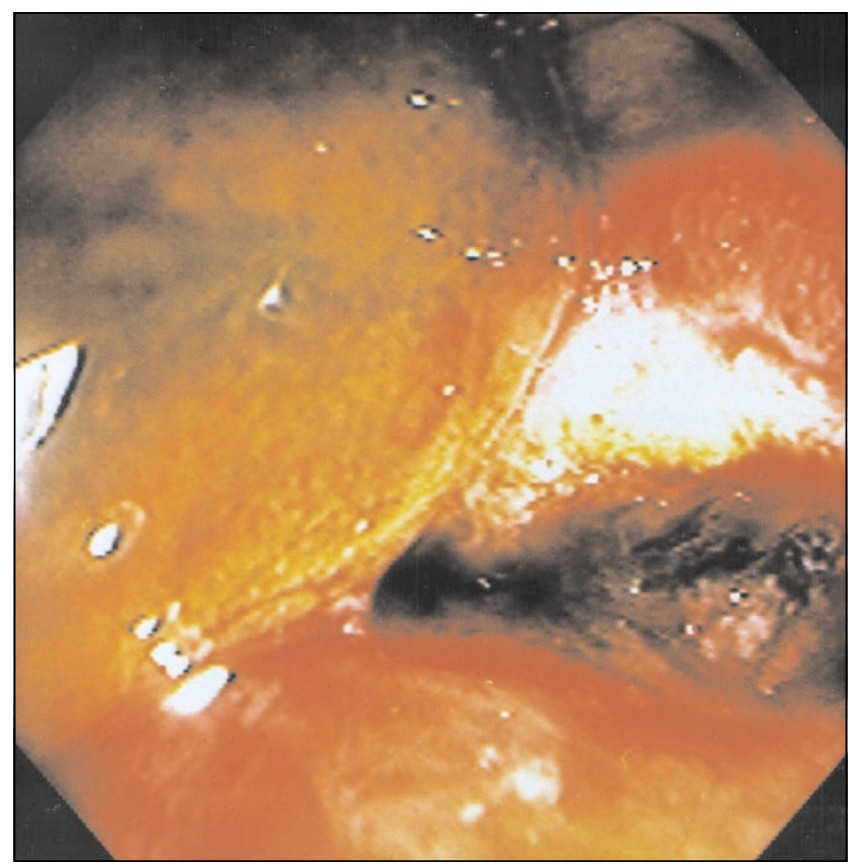

Figure 1) Endoscopic appearance of gallstone in the duodenum

\section{CASE PRESENTATION}

An 83-year-old man presented with a two-week history of epigastric and right upper quadrant pains associated with anorexia, nausea and mild weight loss. Eventually he developed recurrent vomiting necessitating admission to hospital. He denied fever, jaundice, hematemesis and melena.

His past medical history included advanced ischemic heart disease, mild renal insufficiency, chronic normocytic normochromic anemia and gout, as well as a 40-year history of ulcerative colitis. Two years earlier, a cecal tubulovillous adenoma was removed by colonoscopy, and inactive universal ulcerative colitis was confirmed with no evidence of dysplasia on multiple random biopsies. Incidental cholelithiasis and an otherwise normal biliary tree were shown by abdominal ultrasound at that time. His medications consisted of enteric coated acetylsalicylic acid, captopril, furosemide, allopurinol and iron tablets. He did not smoke or drink alcohol.

On examination he looked pale and unwell but was stable hemodynamically with no signs of heart failure or jaundice. His temperature was $38.2^{\circ} \mathrm{C}$. Mild right upper quadrant tenderness without rebound tenderness could be elicited. There were no masses or organomegaly. Rectal examination suggested prostatic hypertrophy. Initial laboratory studies revealed hemoglobin $73 \mathrm{~g} / \mathrm{L}$ (normal 133 to $169 \mathrm{~g} / \mathrm{L}$ ), normal white blood cell count, alkaline phosphatase $505 \mathrm{U} / \mathrm{L}$ (normal 39 to $117 \mathrm{U} / \mathrm{L}$ ), alanine aminotransferase $45 \mathrm{U} / \mathrm{L}$ (normal 0 to $40 \mathrm{U} / \mathrm{L}$ ), aspartate aminotransferase $62 \mathrm{U} / \mathrm{L}$ (normal 7 to $37 \mathrm{U} / \mathrm{L}$ ), total bilirubin $10 \mu \mathrm{mol} / \mathrm{L}$ (normal 4 to $18 \mu \mathrm{mol} / \mathrm{L}$ ), serum creatinine $219 \mu \mathrm{mol} / \mathrm{L}$ (normal 60 to $120 \mu \mathrm{mol} / \mathrm{L}$ ) and normal electrolytes. Evaluation of his anemia showed normal serum B12 and red cell folate levels. The results of iron studies agreed with those for anemia of chronic disease.

An ultrasound showed a slightly thickened gallbladder wall, cholecystolithiasis and air in the intrahepatic bile

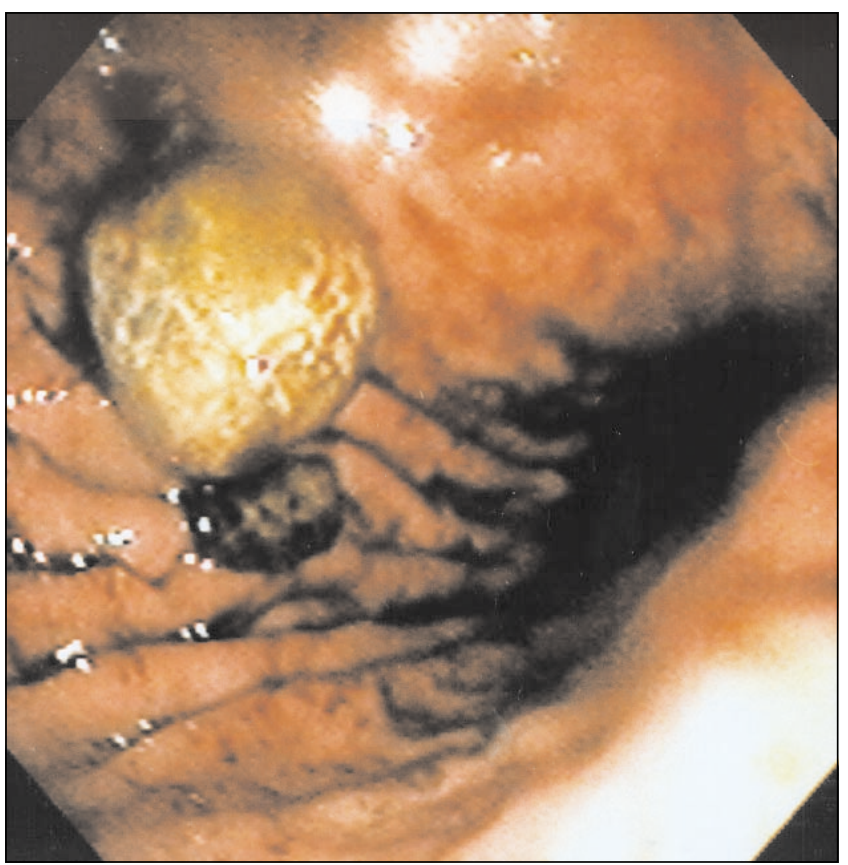

Figure 2) Gallstone along greater curvature of gastric body

ducts. An endoscopic retrograde cholangiopancreatography revealed a small amount of fresh blood in the stomach in the absence of any esophageal or gastric lesions. Intubation of the duodenum was prevented by a large gallstone impacted in the first part of the duodenum (Figure 1).

The stone was pulled back into the stomach by using a polypectomy snare (Figure 2). The duodenoscope was then advanced into the duodenum. An oval shaped ulcer was noted in the duodenal apex with a small fistulous opening draining green bile when endoscopic suction was applied (Figure 3). The proximal portion of the descending duodenal limb appeared stenotic but permitted passage of the duodenoscope (Figure 4). The papilla appeared normal, and the pancreatiogram was unremarkable. Upon cannulation of the fistula, a cholangiogram was obtained, confirming air in the biliary tree, no evidence of ductal abnormalities and a patent cystic duct. The gallbladder could not be outlined fully due to back-leakage of contrast medium through the large fistulous orifice, as well as some extravasation of hypaque around the gallbladder suggesting a localized rupture of the cystic duct and, less likely, the gallbladder wall (Figure 5). Thereafter, with the use of a forward viewing gastroscope, the stone in the gastric lumen was grasped with a snare once more and removed orally together with the endoscope (Figure 6), encountering moderate resistance at the level of the cricopharyngeus. The stone was smooth and measured $2.7 \mathrm{~cm}$ in maximum diameter (Figure 6).

The patient was transfused and placed on a 10-day course of intravenous antibiotics, as well as oral omeprazole $40 \mathrm{mg} /$ day. His symptoms completely disappeared, and his liver enzymes normalized three weeks later. Five months later he remained asymptomatic and had gained $6.8 \mathrm{~kg}$. A repeat ultrasound showed cholelithiasis and a thickened gallbladder wall without evidence of bile duct dilation or intrabiliary air. 


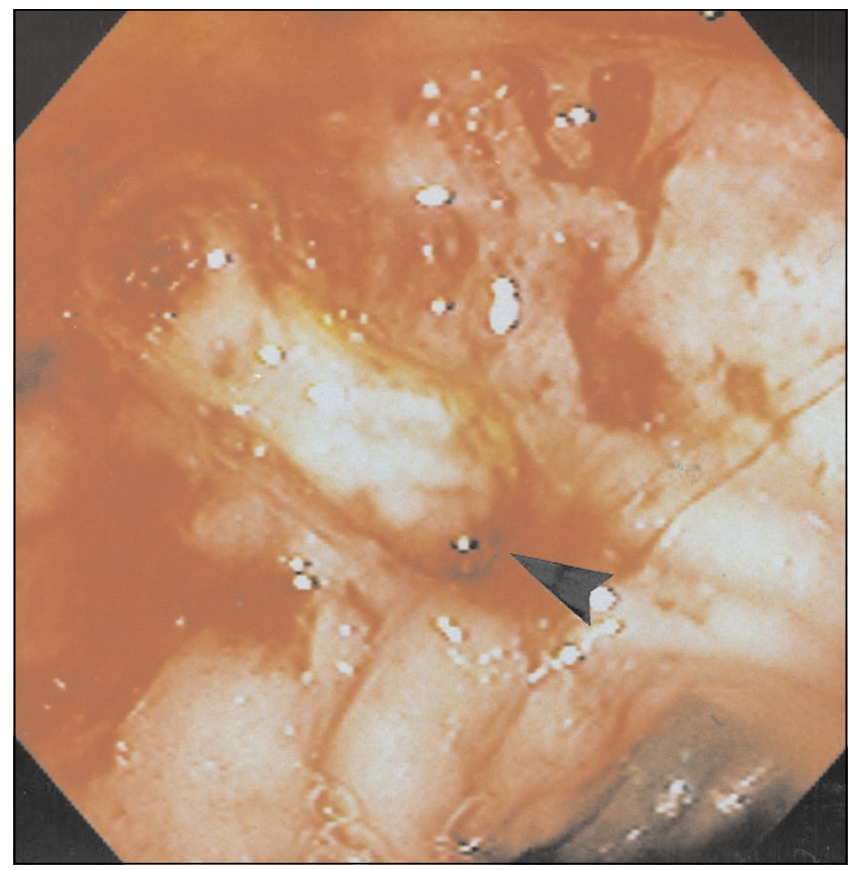

Figure 3) Oval-shaped ulceration surrounded by marked erythema and friability. Fistulous opening (arrowhead)

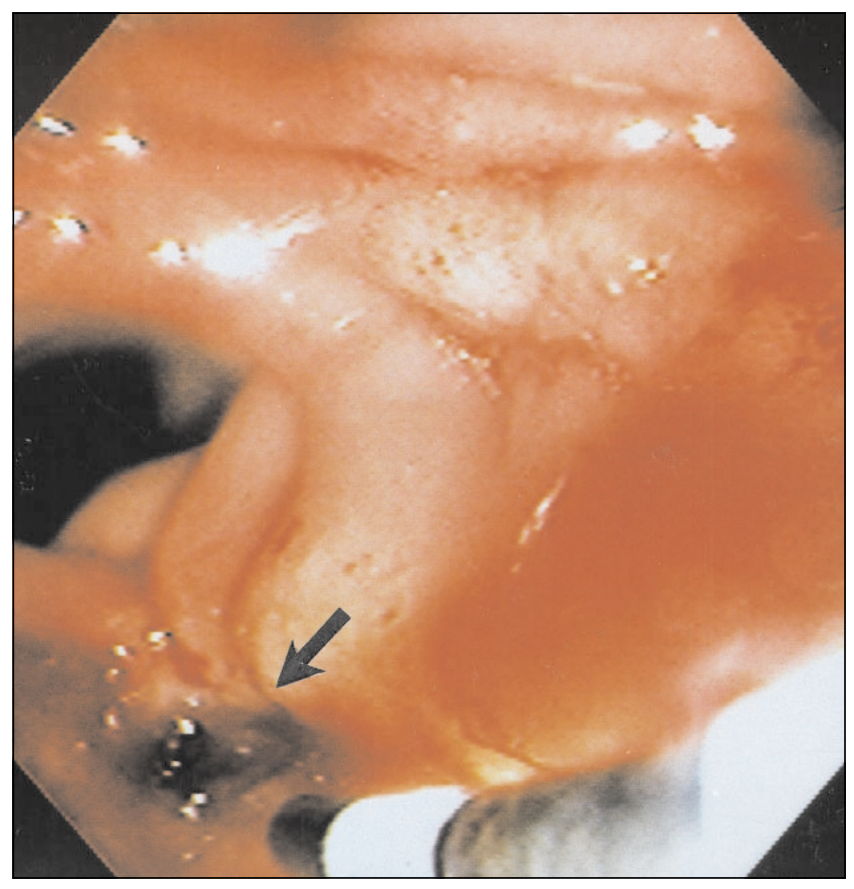

Figure 4) Stenotic proximal portion of descending duodenum. Cannula points towards cholecystoduodenal fistua (arrow)

\section{DISCUSSION}

Biliary-enteric fistulas form in $0.3 \%$ to $0.5 \%$ of all patients with gallstones, accounting for $1 \%$ to $3 \%$ of cases of mechanical small intestinal obstruction (3). A fistulous communication occurs between the gallbladder (or rarely the bile duct) and the duodenum in approximately $70 \%$ of cases. Fistulas into the colon, jejeunum and stomach occur much less frequently $(4,5)$.

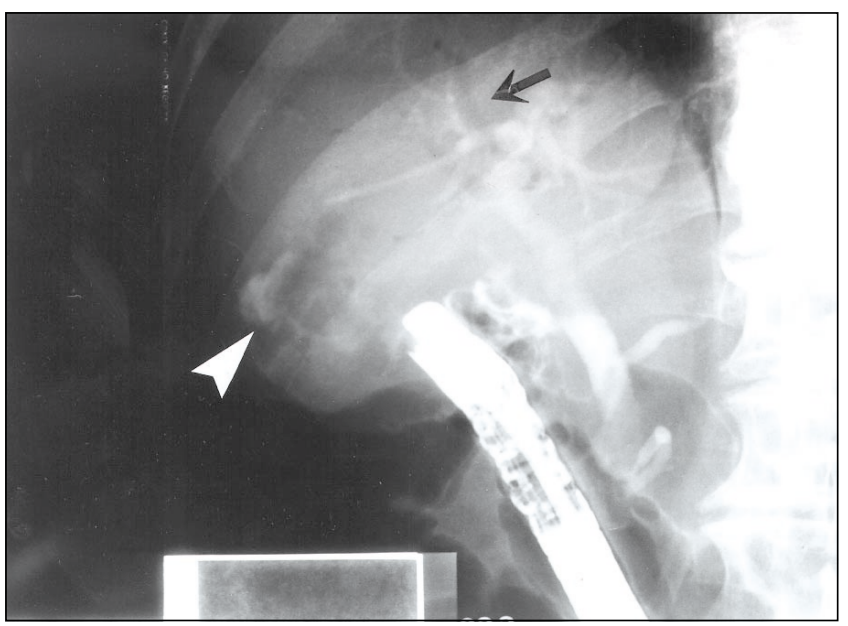

Figure 5) Endoscopic retrograde cholangiopancreatography showing air in biliary tree (arrow) and contrast in the subhepatic space (arrowhead)

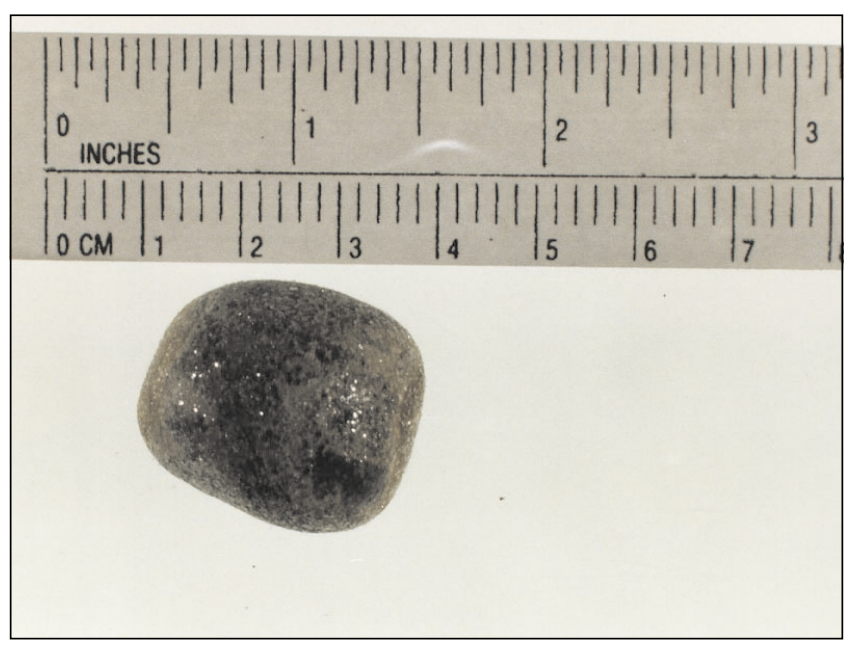

Figure 6) The recovered gallstone with a smooth green-black surface

Acute pericholecystic inflammation results in the formation of adhesions between the gallbladder and the intestine. Most often, large solitary stones cause a chronic inflammatory process leading to localized ischemia of the gallbladder wall. As intraluminal pressure increases, necrosis of the biliodigestive barrier ensues resulting in the formation of a fistula (6).

Stones less than $2.5 \mathrm{~cm}$ in diameter usually pass spontaneously, whereas larger stones lead to obstructive symptoms because they lodge in the terminal ileum in $73 \%$, and in the proximal ileum or jejeunum in $14 \%$ of cases (5). Duodenal obstruction is rare and occurs in about $3 \%$ of patients with gallstone ileus (3).

As in our patient, the clinical presentation of Bouveret's syndrome is often nonspecific, reflecting gastric outlet obstruction, which is frequently incomplete and includes symptoms such as nausea, vomiting and epigastric pain. A pre-existing history of symptomatic biliary tract disease can often be elicited (7). Dehydration and electrolyte abnor- 
malities result from vomiting. Affected patients are usually elderly, and approximately $80 \%$ have concomitant, sometimes debilitating chronic diseases, thus increasing their risk for surgery $(3,8)$.

Upper gastrointestinal hemorrhage in patients with Bouveret's syndrome has been reported in only five patients, originating from duodenal ulceration in four (1,8-10) and from an eroded cystic artery in one (6). Perforation of the duodenum by a large gallstone has also been described (11).

Although the diagnosis of Bouveret's syndrome is often established only intraoperatively, several radiological signs may suggest it. These include air or radiographic contrast in the biliary tree, demonstration of a stone on plain $\mathrm{x}$-ray or upper gastrointestinal series, change in position of a previously known gallbladder stone and a dilated gas-filled stomach (12). The diagnosis of Bouveret's syndrome was established recently by computed tomography scanning in two cases $(12,13)$.

Upper endoscopy has greatly facilitated the preoperative recognition of gastric outlet obstruction due to a large gallstone (14-22), and several authors have attempted endoscopic removal of the stone but were unsuccessful due to its

\section{REFERENCES}

1. Heyd RL, Solinger MR, Howard AL, Rosser JC. Acute upper gastrointestinal hemorrhage caused by gallstone impaction in the duodenal bulb. Dig Dis Sci 1992;37:452-5.

2. Kurtz RJ, Heimann TM, Beck AR, Kurtz AB. Patterns of treatment of gallstone ileus over a 45 year period. Am J Gastroenterol 1985;80:95-8.

3. Day EA, Marks C. Gallstone ileus. Review of the literature and presentation of thirty-four new cases. Am J Surg 1975;129:552-8.

4. Glenn F, Reed C, Grafe WR. Biliary enteric fistula. Surg Gynecol Obstet 1981;153:527-31.

5. Clavien PA, Richon J, Burgan S, Rohner A. Gallstone ileus. Br J Surg 1990;77:737-42.

6. Heinrich D, Meier J, Wehrli H, Buhler H. Upper gastrointestinal hemorrhage preceding development of Bouveret's syndrome. Am J Gastroenterol 1993;88:777-80.

7. Torgerson SA, Greening GK, Juniper K. Gallstone obstruction of duodenal cap (Bouveret's syndrome) diagnosed by endoscopy. Am J Gastroenterol 1979;72:165-7.

8. Chait MM, Lerner AG. Bouveret's syndrome presenting as upper gastrointestinal hemorrhage. Am J Gastroenterol 1986;81:1199-201.

9. Blanchi A, Aleksandrowicz K, Dulbecco P. Une cause rare d'hemorragie digestive haute diagnostique par l'endoscopie. Presse Med 1988;17:33.

10. Salah-Eldin AA, Ibrahim MAH, Alapati R. The Bouveret syndrome: an unusual cause of hematemesis. Henry Ford Hosp Med J 1990;38:52-4.

11. Thomas TL, Jaques PF, Weaver PC. Gallstone obstruction and perforation of the duodenal bulb. Br J Surg 1976;63:131-2. size $(6,19,22,23)$. There is only a single case report from Italy where endoscopic extraction was accomplished (15). In another report, abdominal surgery was avoided by breaking up a duodenal gallstone using ultrasound-guided extracorporeal shock-wave lithotripsy before endoscopic extraction of the fragments (23).

In our patient, a large stone was found in the first part of the duodenum. Following its endoscopic removal, the fistula between the duodenum and the gallbladder was identified. A retrograde cholangiogram confirmed the fistulous connection as well as the absence of choledocholithiasis.

Because the patient remains asymptomatic and there was no intrabiliary air seen on a follow-up ultrasound, we assume that his fistula has closed. Being a high risk surgical patient, we elected to follow this patient and he currently remains asymptomatic.

The treatment for Bouveret's syndrome usually consists of surgical removal of the ectopic gallstone by enterolithotomy followed by fistula repair and cholecystectomy (1). However, as demonstrated in this report, endoscopic stone extraction is possible in selected cases, thus providing a valid alternative therapy for elderly, chronically debilitated patients.

12. Cooper SG, Sherman SB, Steinhardt JE, Wilson JM, Richman AH. Bouveret's syndrome: diagnostic considerations. JAMA $1987 ; 258: 226-8$

13. Murthy GD. Bouveret's syndrome. Am J Gastroenterol 1995;90:638-9.

14. Ah-Chong K, Leong YP. Gastric outlet obstruction due to gallstones (Bouveret's syndrome). Postgrad Med J 1987;63:909-10.

15. Bedogni G, Contini S, Meinero M, Pedrazzoli C, Piccinini GC. Pyloroduodenal obstruction due to biliary stone (Bouveret's syndrome) managed by endoscopic extraction. Gastrointest Endosc 1985:31;36-8

16. Ryska M, Prochazka M, Skala J, Mottle V. Gallstone pyloroduodenal obstruction - fibroscopic diagnosis. Acta Chir Scand 1985;151:191-2.

17. Ayub A, Michalko CH. Gallstone obstruction of the pylorus. Gastrointest Endosc 1982;28:25-6.

18. Weingart J, Wilhem A, Ottenjann R. Obstruction of the duodenal bulb caused by gallstone perforation. Endoscopy 1979;3:190-2.

19. Bottari M, Pallio S, Scribano E, Certo A. Pyloroduodenal obstruction by a gallstone: Bouveret's syndrome. Gastrointest Endosc 1988;34:440-2.

20. Oakland DJ, Denn PG. Endoscopic diagnosis of gallstone ileus of the duodenum. Dig Dis Sci 1986;31:98-9.

21. Van Dam J, Steiger E, Sivak MV. Giant duodenal gallstone presenting as gastric outlet obstruction: Bouveret's syndrome. J Clin Gastroenterol 1992;15:150-3.

22. Tharakan J, Lee FI. Duodenal obstruction due to a gallstone: a case of Bouveret's syndrome. Am J Gastroenterol 1994;89:1917.

23. Holl J, Sackman M, Hoffmann R, et al. Shock-wave therapy of gastric outlet syndrome caused by a gallstone. Gastroenterology 1989;97:472-4. 


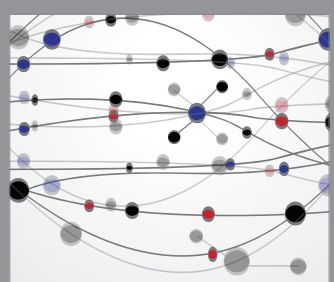

The Scientific World Journal
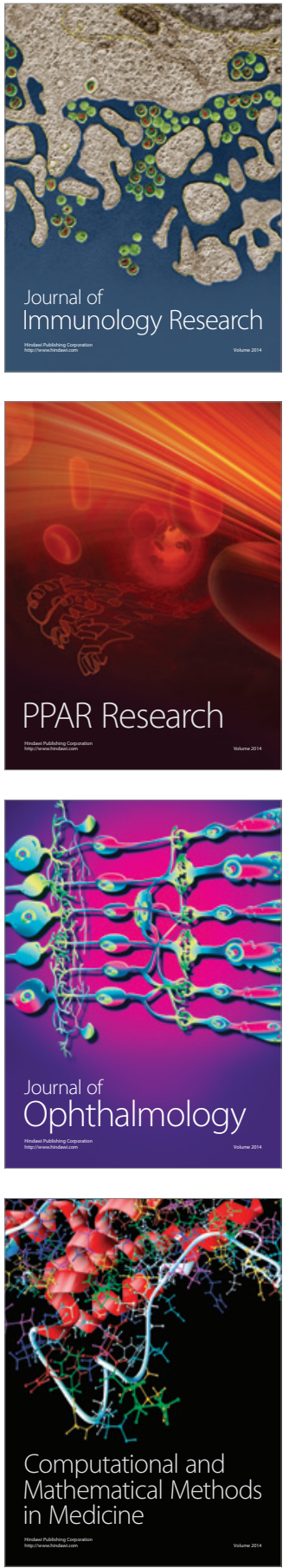

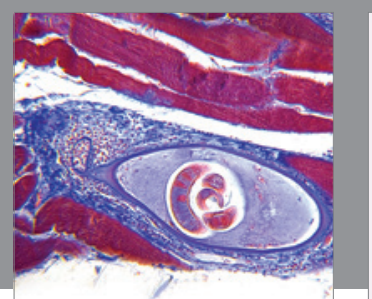

Gastroenterology Research and Practice

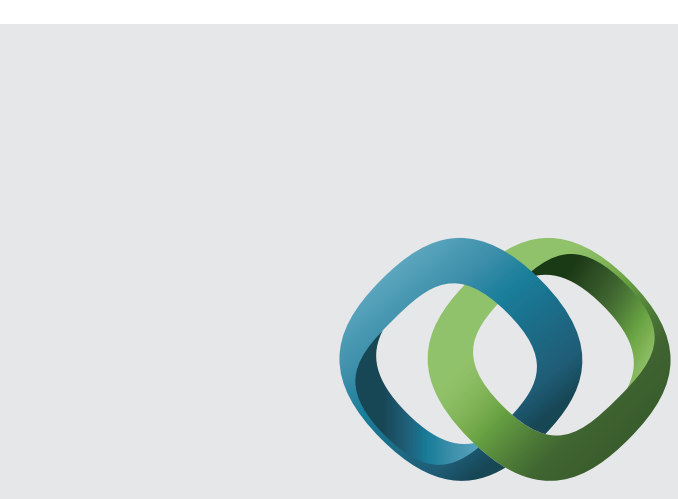

\section{Hindawi}

Submit your manuscripts at

http://www.hindawi.com
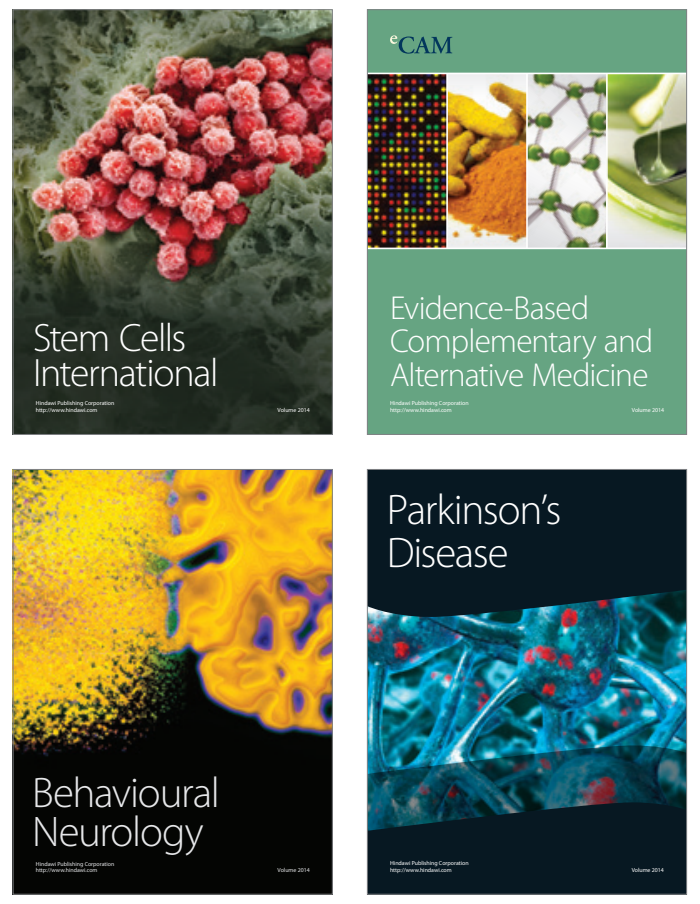
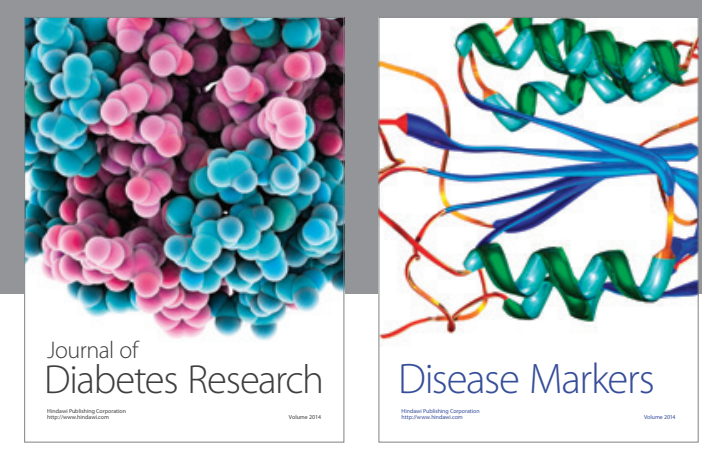

Disease Markers
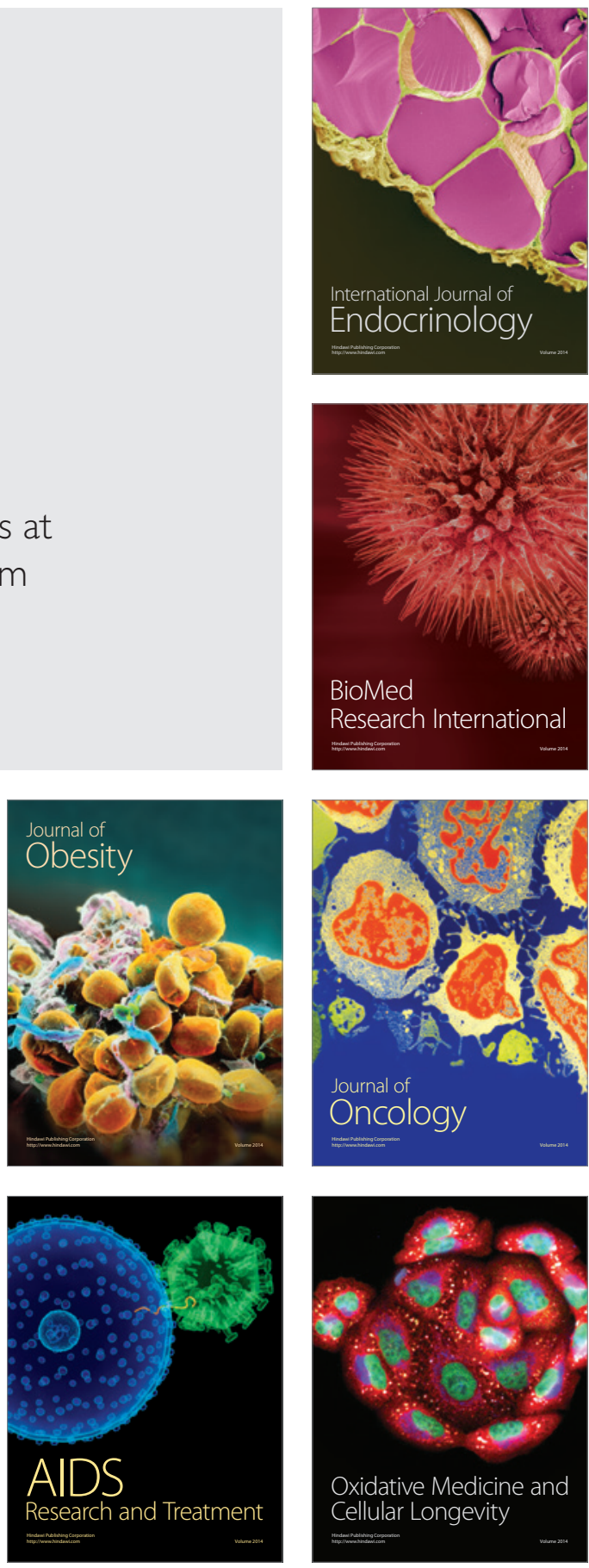